\title{
Correction: The feasibility and acceptability of neuromuscular electrical stimulation to improve exercise performance in patients with advanced cancer: a pilot study
}

Tamara Windholz ${ }^{\dagger}$, Tara Swanson ${ }^{\dagger}$, Brandy L Vanderbyl and R Thomas Jagoe*

\section{Correction}

In the course of type-setting this article [1] for final publication the presentation of the data in Tables 1 and 2 was altered. To avoid any confusion and to improve the clarity of our results the corrected Tables are included here.

\footnotetext{
* Correspondence: thomas.jagoe@mcgill.ca

${ }^{\dagger}$ Equal contributors

Segal Cancer Centre, Jewish General Hospital, 3755 Cote Ste Catherine,

Montreal, QC H3T 1E2, Canada
} 
Table 1 Demographic and disease characteristics of patients who underwent full baseline assessment

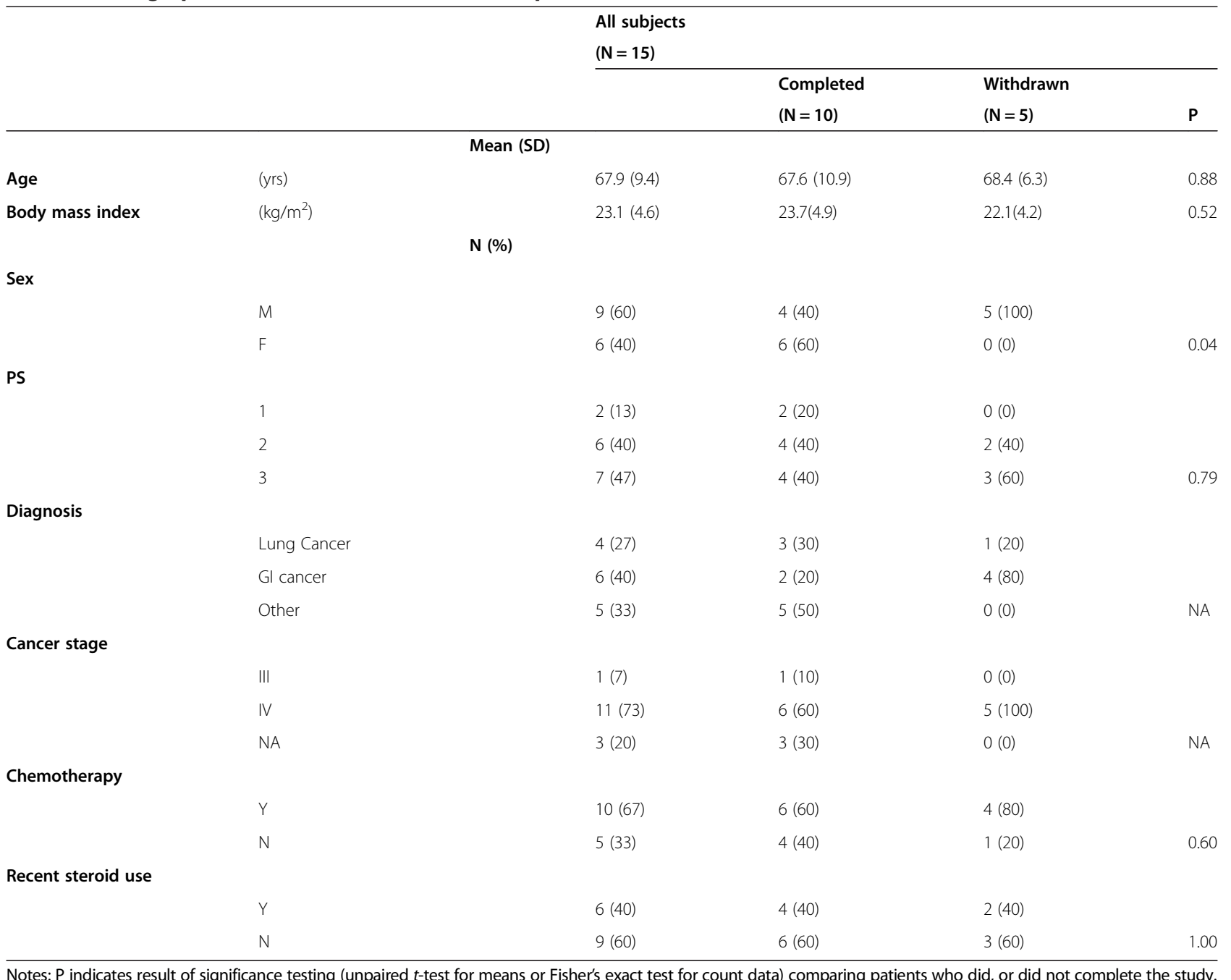

Table 2 Physical performance evaluation results at baseline and after 6 weeks of NMES intervention

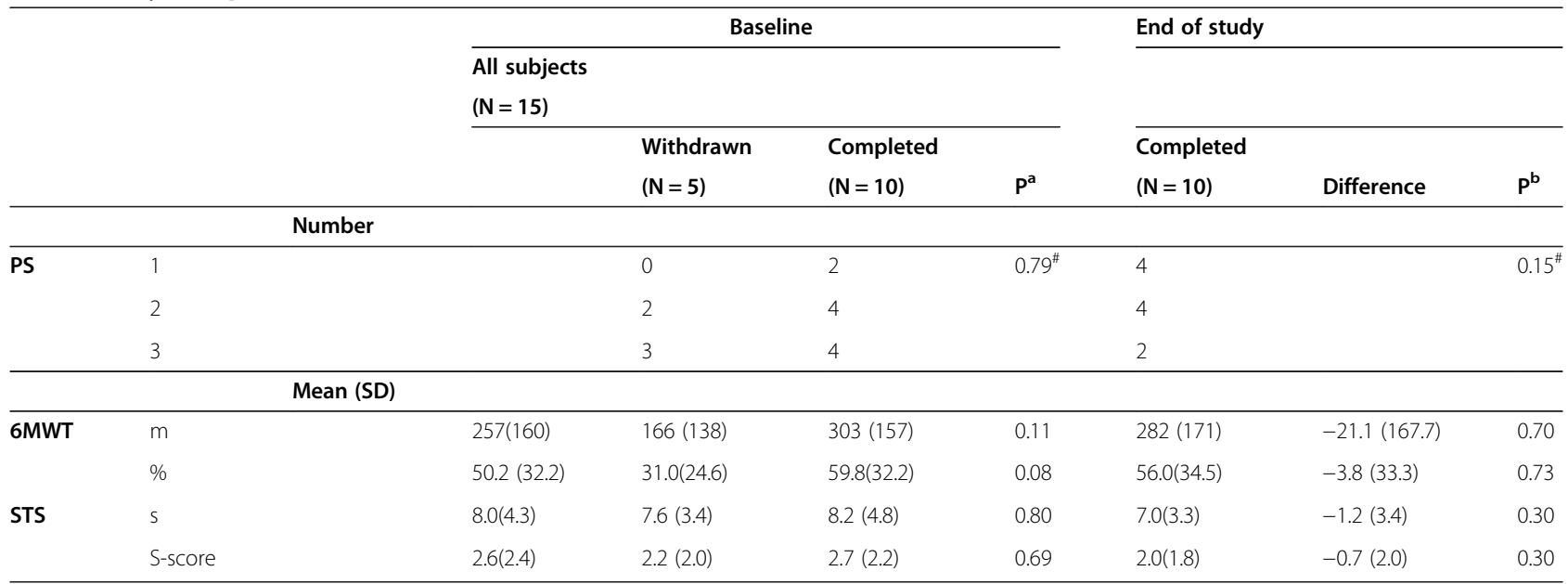

Notes: Performance status (PS), six-minute walk distance (6MWT) in metres (m) and expressed as \% predicted (from [21]), Sit-to-stand (STS) test expressed as seconds (s) and as a standard score (S-score) value calculated using age range-specific mean and standard deviations for healthy controls (from [22]): positive scores indicates STS $\mathrm{S}$-scores above the mean. $\mathrm{P}^{\text {a: }}$ "Fisher's exact (for counts) or unpaired $t$-test (for means) comparing baseline results for patients withdrawn and patients who completed

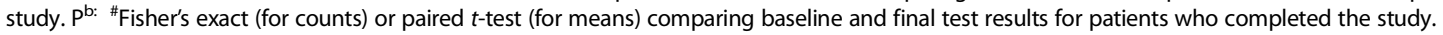


Received: 24 June 2014 Accepted: 25 June 2014

Published: 4 July 2014

\section{Reference}

1. Windholz T, Swanson T, Vanderbyl BL, Jagoe RT: The feasibility and acceptability of neuromuscular electrical stimulation to improve exercise performance in patients with advanced cancer: a pilot study. BMC Palliat Care 2014, 13:23.

doi:10.1186/1472-684X-13-33

Cite this article as: Windholz et al: Correction: The feasibility and acceptability of neuromuscular electrical stimulation to improve exercise performance in patients with advanced cancer: a pilot study. BMC Palliative Care 2014 13:33.

\section{Submit your next manuscript to BioMed Central and take full advantage of:}

- Convenient online submission

- Thorough peer review

- No space constraints or color figure charges

- Immediate publication on acceptance

- Inclusion in PubMed, CAS, Scopus and Google Scholar

- Research which is freely available for redistribution 